\title{
REDISPLACEMENT AFTER MANIPULATION OF DISTAL RADIAL FRACTURES IN CHILDREN
}

\author{
M. T. PROCTOR, D. J. MOORE, J. M. H. PATERSON
}

From the Royal London Hospital, England

We reviewed 68 fractures of the distal radius in children, all treated by primary manipulation and plaster immobilisation.

Complete displacement of the fracture and failure to achieve a perfect reduction were both associated with a significant increase in the chance of redisplacement.

We recommend the use of percutaneous Kirschner wires to maintain a satisfactory position in all cases in which a perfect reduction cannot be achieved.

J Bone Joint Surg [Br] 1993; 75-B:453-4.

Received 20 May 1992; Accepted 9 September 1992

Fractures of the distal radius are among the most common of childhood injuries (Wong 1965), and often require closed reduction under general anaesthesia. Previous publications have concentrated on their potential for remodelling and the amount of residual angulation which is allowable. Friberg $(1979 a, b, c)$ showed that fractures with more than $20^{\circ}$ of dorsal angulation may not remodel completely, but Hughston (1962) stated that, in children less than ten years old, fractures close to the lower end of the radius with $30^{\circ}$ to $40^{\circ}$ of angulation may eventually have excellent function and minimal deformity. Daruwalla (1979) showed that restriction of movement can result from malunion, and suggested that no more than $10^{\circ}$ of angulation should be allowed in children over the age of ten.

The success of manipulative reduction depends on maintaining the corrected position in plaster, but Friberg (1979) showed that redisplacement occurred in as many as half of his cases. Voto, Weiner and Leighley (1990) stated that "presently there exists a paucity of literature on reasons which are likely to contribute to the reangulation/displacement of paediatric forearm fractures".

M. T. Proctor, MA, FRCS, Senior Registrar

D. J. Moore, FRCS, Registrar

J. M. H. Paterson, FRCS, Consultant Orthopaedic Surgeon

Department of Orthopaedic Surgery, The Royal London Hospital, Whitechapel, London El IBB, UK.

Correspondence should be sent to Mr M. T. Proctor at 125 Felsham Road, Putney, London SW 15 IBA, UK.

(C)1993 British Editorial Society of Bone and Joint Surgery $0301-620 \mathrm{X} / 93 / 3551 \$ 2.00$

We report the incidence of redisplacement after closed manipulation and analyse the factors which contribute to loss of the reduced position.

\section{MATERIALS AND METHODS}

We undertook a retrospective study of the notes and radiographs of children admitted to the Royal London Hospital between 1989 and 1991. During this time all displaced distal radial fractures were treated by primary manipulation and immobilisation in plaster. We identified 74 patients under the age of 16 years who had undergone manipulation of a distal radial fracture. The records were incomplete in seven cases, leaving 67 children with 68 fractures.

The following data were recorded: the age, sex and ethnic origin of the patient, the cause of the injury, the experience of the surgeon who performed the reduction (senior or junior registrar), and the type of plaster applied (below or above elbow, full plaster or backslab). The radiographs were all reviewed by a single examiner who noted, from the initial radiographs, the distance of the fracture from the articular surface of the radius, the

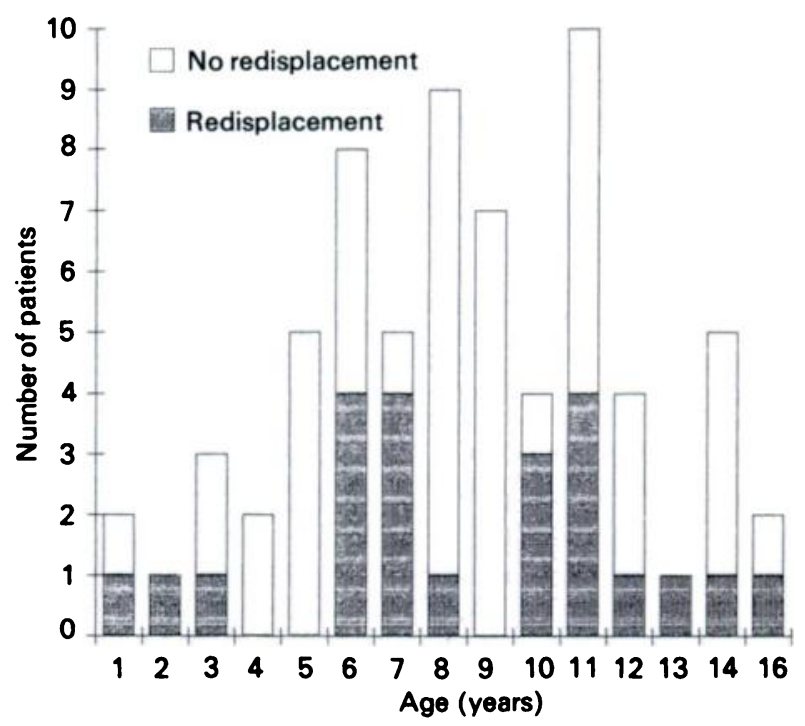

Fig. 1

Age distribution of 67 patients with fractures of the distal radius. 
Table I. Rate of redisplacement related to type of fracture and success or failure of reduction

\begin{tabular}{lc}
\hline & $\begin{array}{l}\text { Redisplacement } \\
\text { (per cent) }\end{array}$ \\
\hline Perfect reduction & \\
Incompletely displaced fractures & 5 \\
Completely displaced fractures & 20 \\
& \\
Imperfect reduction & 43 \\
Incompletely displaced fractures & 73 \\
Completely displaced fractures &
\end{tabular}

initial angulation and degree of apposition of the fracture, and the presence or absence of a fracture of the distal ulna. In every case, we examined the pre- and postmanipulation films and the final radiograph. If remanipulation had been performed the films taken before and after were also examined. Each radiograph was measured and the dorsal or volar angulation, the radial or ulnar angulation and the percentage apposition of the fracture were recorded.

In all cases, the initial manipulation had been performed because the fracture was completely displaced or angulated more than $20^{\circ}$. We defined redisplacement as recurrence of more than $20^{\circ}$ of angulation, or less than $50 \%$ apposition of the fragments.

\section{RESULTS}

Redisplacement had occurred in 23 fractures $(34 \%)$. Seven had no further procedure; a second reduction was undertaken in 16. Nine of the 16 had closed or open reduction and stabilisation with Kirschner wires and seven had remanipulation and plaster fixation. An acceptable position was achieved in four of the seven patients.

Patient-related factors. Figure 1 shows the distribution of the fractures and of those which redisplaced in relation to age. We were unable to show an association between the age of the child and the likelihood of redisplacement or between redisplacement and sex, ethnic origin or cause of injury.

Fracture-related factors. Of the 25 fractures which were initially completely displaced, 13 redisplaced; of the 43 incompletely displaced fractures only ten redisplaced $(\mathrm{p}=0.03)$.

A fracture of the ulna did not itself increase the risk of redisplacement but was closely associated with complete displacement of the radial fracture. Of the 25 fractures which were completely displaced, 24 had an ulnar fracture and in 17 this was displaced.

Neither the site of the fracture (distance from the articular surface of the radius) nor the initial angulation was shown to be significant.

Treatment-related factors. No association was shown between redisplacement and the experience of the surgeon or the type of plaster applied.

A perfect reduction was achieved in nearly the same proportion of completely displaced and incompletely displaced fractures (10/25 and 22/43). In both groups, failure to achieve a perfect reduction was associated with redisplacement. In the initially completely displaced fractures there were ten perfect reductions, two of which redisplaced, and 15 imperfect reductions, 11 of which redisplaced $(p=0.03)$. In the initially incompletely displaced fractures there were 22 perfect reductions, one of which redisplaced, and 21 imperfect reductions, nine of which redisplaced $(p=0.009)$.

The effect of the two significant factors, complete initial displacement and failure to achieve a perfect reduction, is summarised in Table $\mathrm{I}$.

\section{DISCUSSION}

We have identified two factors which increase the chance of redisplacement of forearm fractures in children, the presence of complete displacement and failure to achieve a perfect reduction. Previously, Gupta and Danielsson (1990) reported that redisplacement may be linked to the position of immobilisation in plaster and Voto et al (1990) suggested that redisplacement may be due to a loose cast. From our retrospective study we are unable to comment on the quality of the plaster fixation. Our findings have persuaded us to modify the initial management of these fractures. We do not now accept anything less than a perfect reduction. If incompletely displaced fractures are perfectly reduced there is a $5 \%$ chance of redisplacement, but there is a $43 \%$ chance if reduction is poor. For completely displaced fractures the equivalent figures are $20 \%$ and $73 \%$.

We now use percutaneous Kirschner wire fixation in those patients in whom anatomical reduction cannot be achieved and who are therefore at risk of redisplacement.

No benefits in any form have been received or will be received from a commercial party related directly or indirectly to the subject of this article.

\section{REFERENCES}

Daruwalla JS. A study of radioulnar movements following fractures of the forearm in children. Clin Orthop 1979; 139:114-20.

Friberg KSI. Remodelling after distal forearm fractures in children. I. The effect of residual angulation on the spatial orientation of the epiphyseal plates. Acta Orthop Scand 1979a ; 50:537-46.

Friberg KSI. Remodelling after distal forearm fractures in children. II. The final orientation of the distal and proximal epiphyseal plates of the radius. Acta Orthop Scand 1979b: 50:731-9.

Friberg KSI. Remodelling after distal forearm fractures in children. III. Correction of residual angulation in fractures of the radius. Acta Orthop Scand 1979c; 50:741-9.

Gupta RP, Danielsson LG. Dorsally angulated solitary metaphyseal greenstick fractures in the distal radius: results after immobilisation in pronated, neutral or supinated position. J Paed Orthop 1990; 10:90-2.

Hughston JC. Fractures of the forearm in children. J Bone Joint Surg [Am] 1962; 44-A :1678-93.

VotoSJ, Weiner DS, Leighley B. Redisplacement after closed reduction of forearm fractures in children. J Pediatr Orthop 1990; 10:79-84.

Wong PC. A comparative epidemiologic study of fractures among Indian, Malay and Swedish children. Med J Malaya 1965: 20: 132-43. 